\title{
Improving the Geomechanics Conditions for Effective Ground Control; A Case Study of Chibuluma South Mine, Zambia
}

\author{
Pardon SINKALA ${ }^{1, a}$, Radhe KRISHNA ${ }^{2, b}$ \\ 1,2University of Zambia, School of Mines, PO Box 32379, Lusaka Zambia

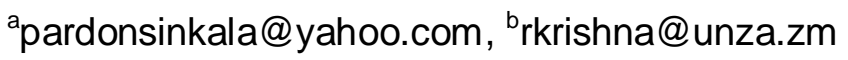

Keyword: Rockmass, Characterization, Classification, Design methods, Ground control.

\begin{abstract}
Statistical studies at Chibuluma South mine have indicated that $70 \%$ of the falls of ground were recorded in the decline, orebody drives, access crosscuts and longhole stopes from the year 2009 to 2013. This study was therefore carried out to propose a strategy that will improve the performance of ground stabilization at Chibuluma South mine in order to ensure a safe and costeffective extraction of ore. To review and improve the ground support installed at the mine, various stages of the support design process were followed. These were; data collection, rockmass characterization, rockmass classification, empirical and analytical design methods, numerical design methods, ground support monitoring and finally the design of reviewed ground support system. A number of software tools were used in the study. These were; (1) RocLab, for determination of rock strength parameters, (2) Dips, for analysis of joints, (3) Phase2, for Insitu and induced stress analysis (4) Unwedge, for determination of potential unstable wedges around excavations and support pattern design. The objective of this study was met, and ground support recommendations were also made in the study.
\end{abstract}

\section{Introduction}

This study was conducted at Chibuluma south mine which is on the Zambian Copperbelt province. The mine is located on latitude $12^{\circ} 53^{\prime} \mathrm{S}$, longitude $28^{\circ} 05^{\prime} \mathrm{E}$, lies at an elevation of $1250 \mathrm{~m}$ above the sea level and is approximately $300 \mathrm{~km}$ north of the capital city, Lusaka. The main objective of this study was to propose a strategy that would improve the performance of ground stabilization at Chibuluma south mine in order to ensure safe and cost-effective extraction of ore.

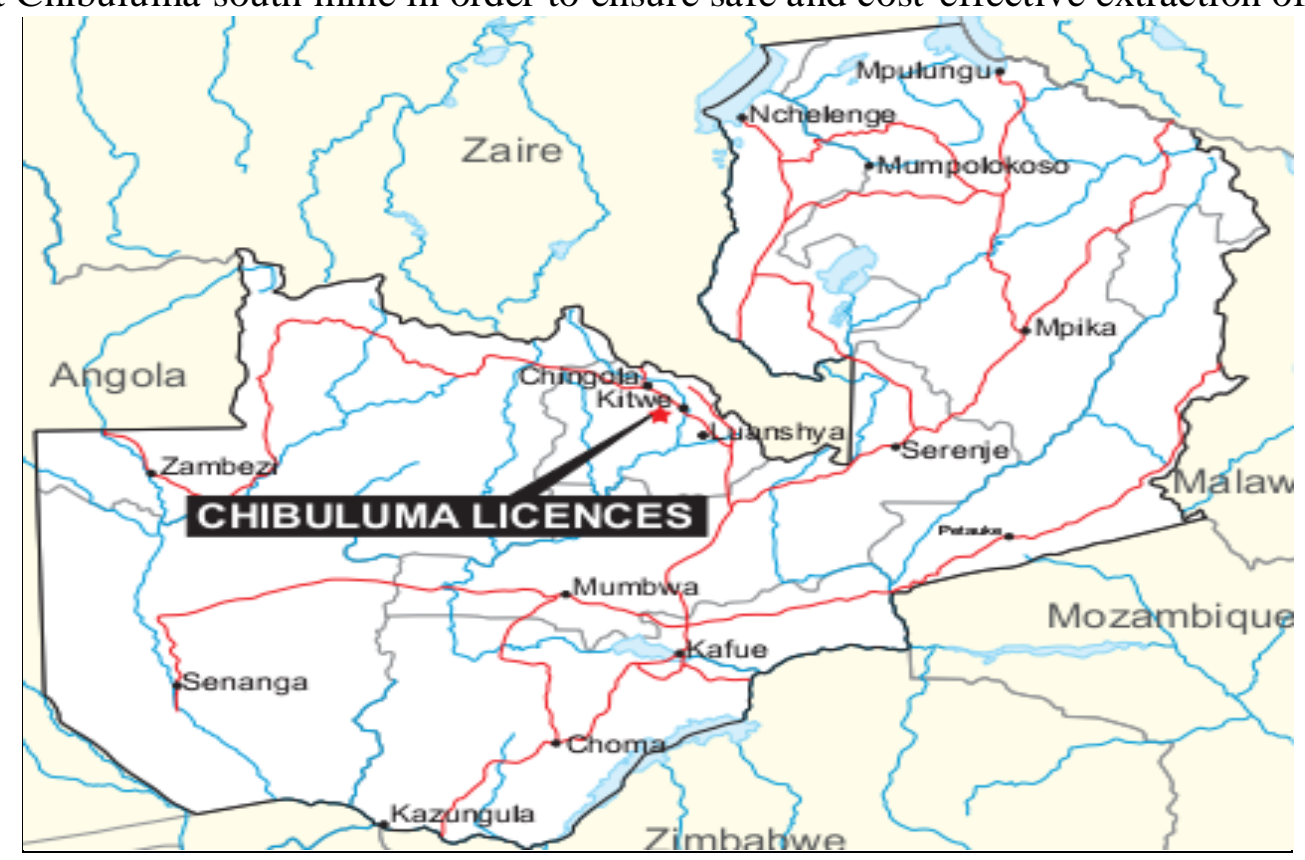

Fig. 1 Site of research shown by the arrow 


\section{Methodology and the rock support design process}

The data collected consisted of geological and geotechnical data. The modes of data collection used were underground joint survey and borehole core logging. Data was collected and analyzed at each of the various stages of the design process shown below;

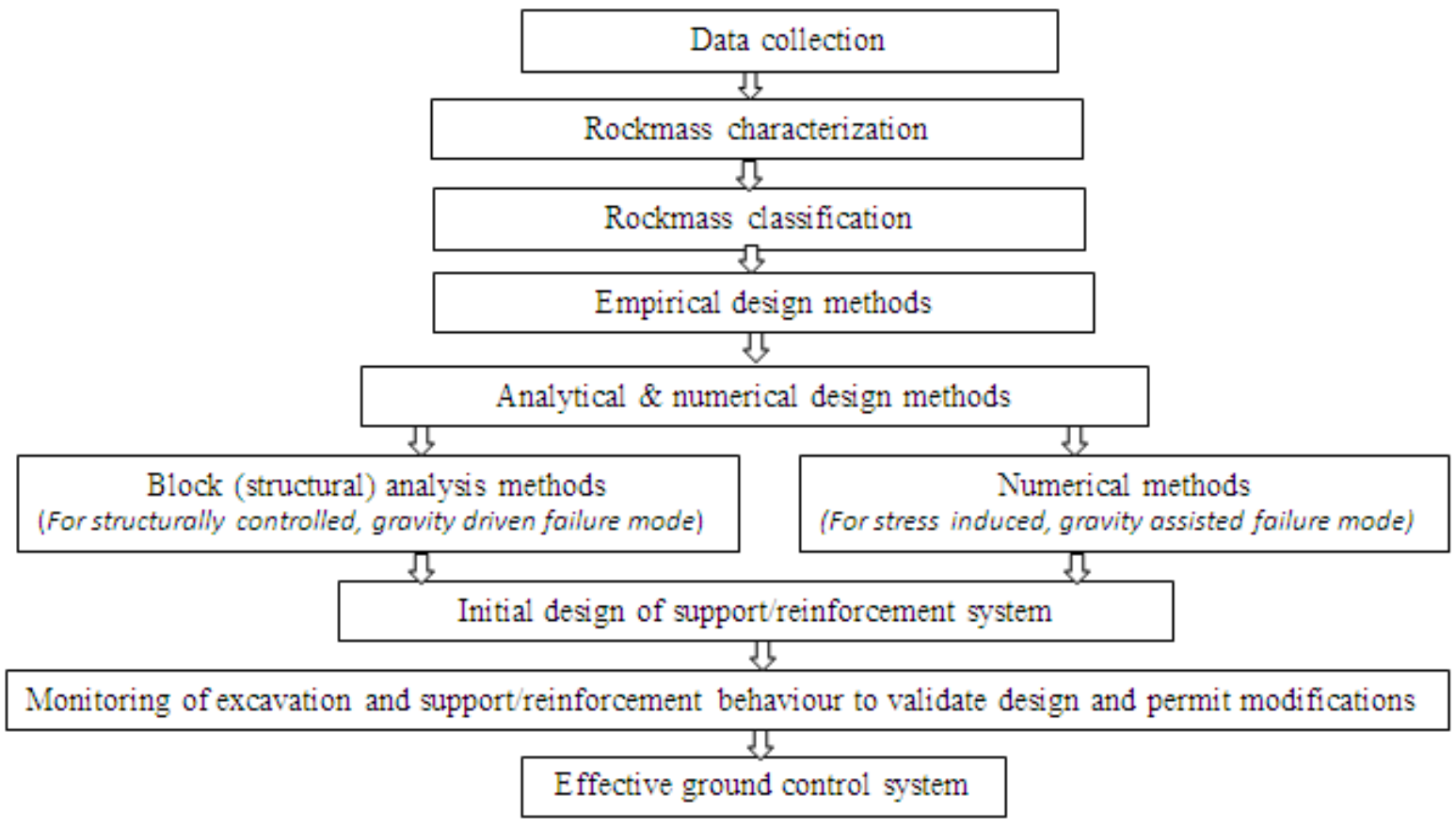

Fig. 2 Support design process

\section{Data analysis and discussion}

The rockmass at Chibuluma south mine was characterized by Rock Quality Designation (RQD) and classified using Geomechanics classification system (Bieniawski's RMR) and the NGI Q System classification.

Q Values

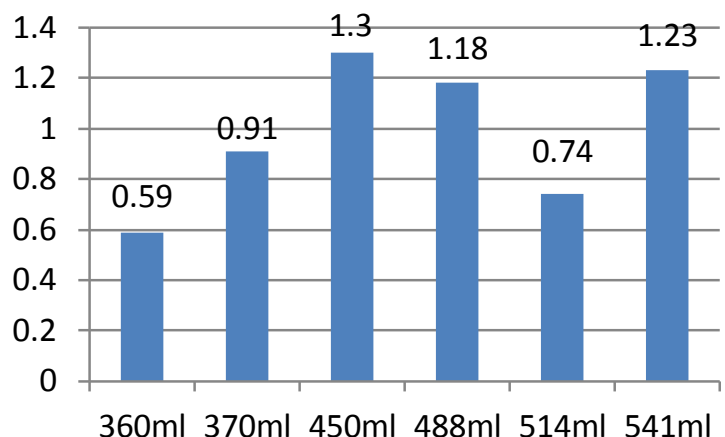

Levels

Fig. 3 Comparison of Q values

\section{RMR}

Values

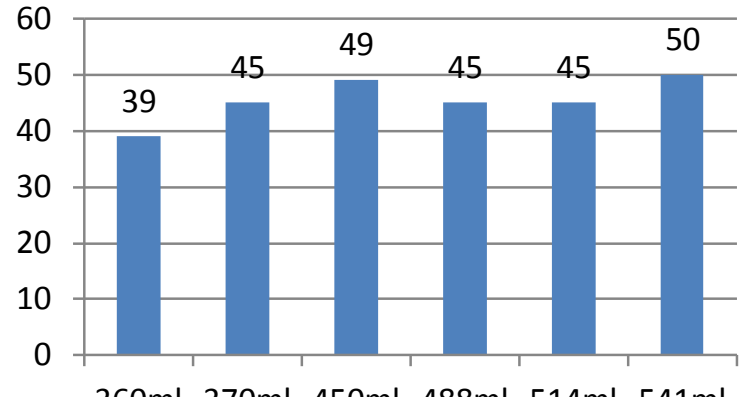

$360 \mathrm{ml} 370 \mathrm{ml} 450 \mathrm{ml} 488 \mathrm{ml} 514 \mathrm{ml} 541 \mathrm{ml}$

Levels

Fig. 4 Comparison of RMR values

\section{Empirical and analytical analyses}

Many empirical equations were used to determine the support parameters of Chibuluma South mine [4,5]. This approach was used to come up with a guide of what is likely about the required support design. Below is an empirical equation (refer with: Eq. 1) that was used to calculate the bolt spacing assuming a square grid pattern of support. 
Bolt spacing $=\left[\frac{\mathrm{FS} \times \text { Support pressure }\left(\text { tonnes } / \mathrm{m}^{2}\right)}{(\text { Bond strength } \times \text { Bolt length })(\text { tonnes })}\right]^{-\frac{1}{2}}$

Where; FS = Design factor of safety

The determination of rockmass parameters using RocLab is based on Hoek - Brown and Mohr Coulomb failure criteria.

\section{Analysis of induced stresses using Phase2 software}

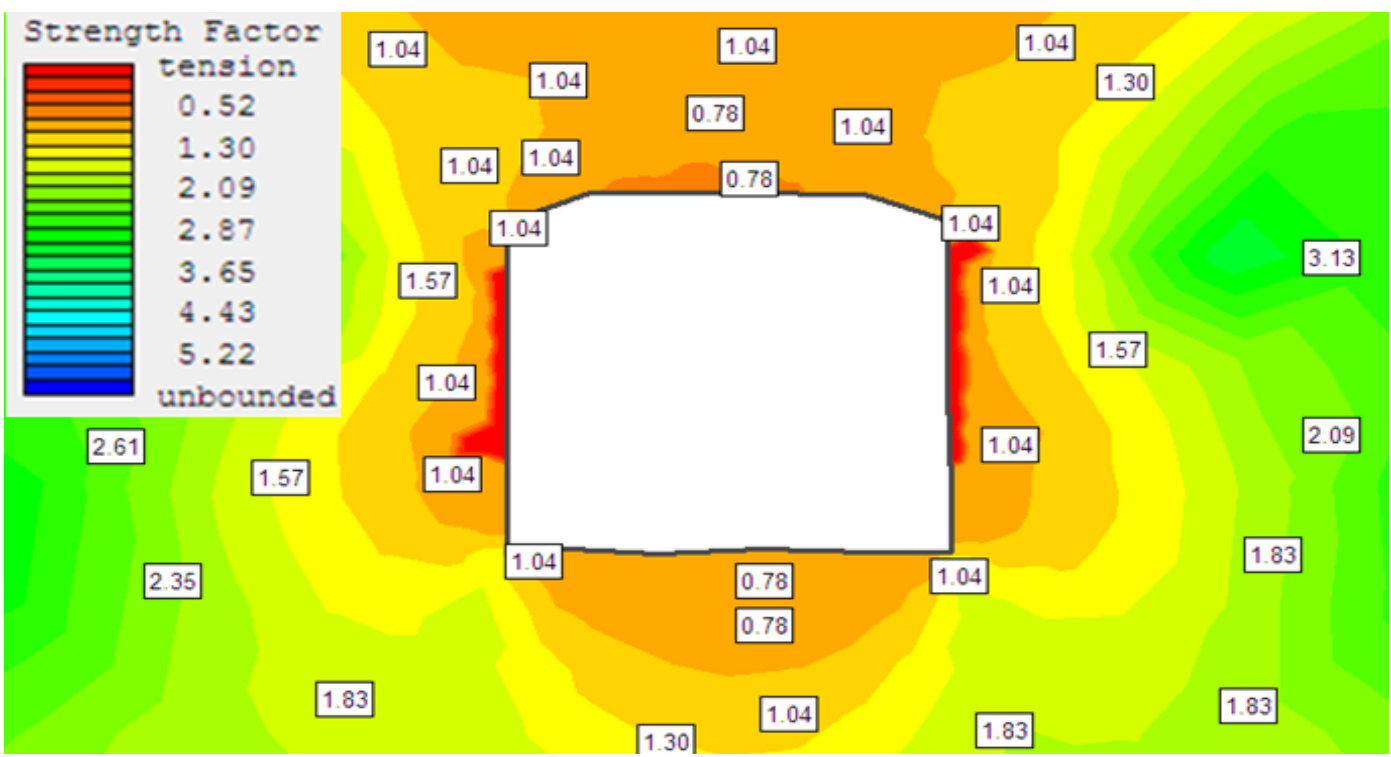

Fig. 4 Distribution of strength factors at $541 \mathrm{ml}$

Table 2. Induced stress analysis - summary

\begin{tabular}{|c|c|c|c|c|}
\hline Level & $\begin{array}{c}\text { Maximum major } \\
\text { principle stress }\end{array}$ & $\begin{array}{c}\text { Virgin stress } \\
0.027 \mathrm{MPa} / \text { meter depth }\end{array}$ & Global Strength & $\begin{array}{c}\text { Minimum } \\
\text { Strength Factor }\end{array}$ \\
\hline $360 \mathrm{~mL}$ & $18.80 \mathrm{MPa}$ & $9.72 \mathrm{MPa}$ & $15.658 \mathrm{MPa}$ & 0.78 \\
\hline $541 \mathrm{~mL}$ & $24.00 \mathrm{MPa}$ & $14.61 \mathrm{MPa}$ & $17.040 \mathrm{MPa}$ & 0.95 \\
\hline
\end{tabular}

From this analysis, it was shown that higher stresses act on the backs of excavations while low stresses act on the sidewalls. This indicates a reduced demand for support in the sidewalls as compared to the roof. Fracture zones around excavations are caused by a combination of induced stresses and blast damage. The failure mode at Chibuluma south mine is stress induced, structurally controlled and gravity assisted failure mode. Below are photographs depicting the rock failure mode at Chibuluma south mine, (refer with: Fig. 5, Fig 6)

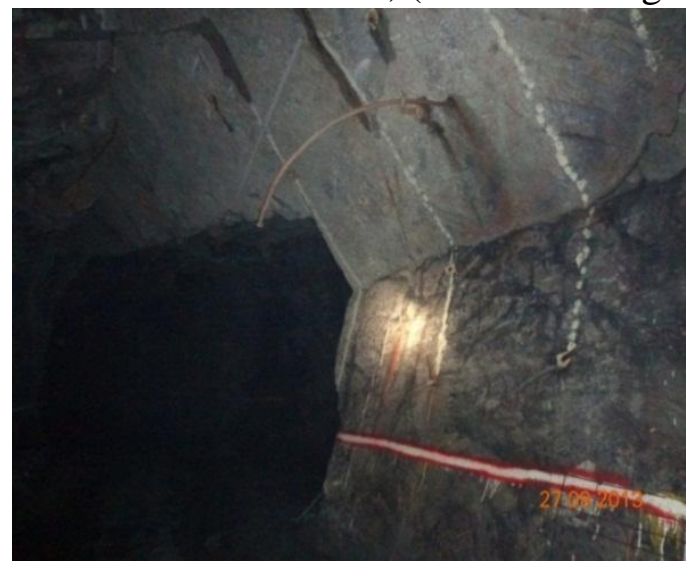

Fig. 5342 metre level room crosscut

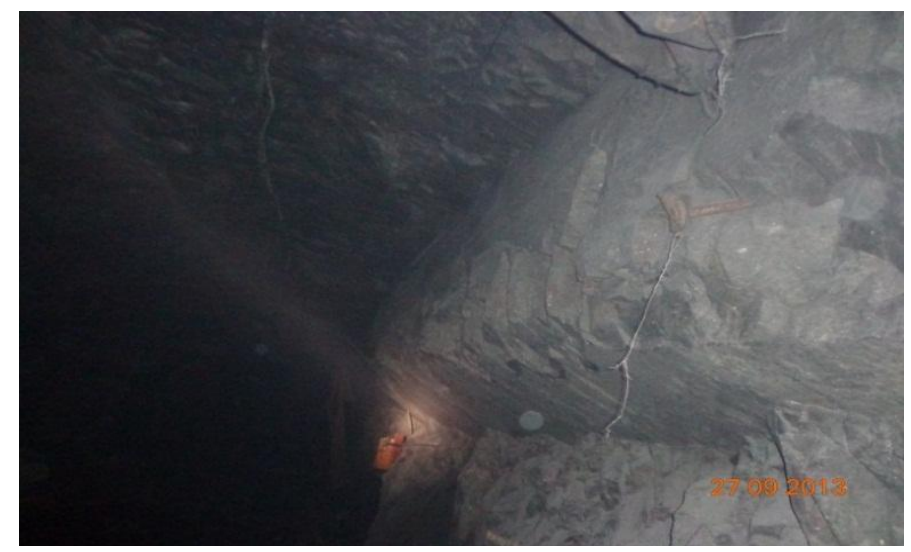

Fig. 6488 metre level mining drive west sidewall 


\section{Structural analysis}

The stereographic plot below (refer with: Fig. 7) represented the major joint sets for 541metre level, southern access from gathering drive to 551 access intersection B7932 and was used as an input data for UNWEDGE software to display the potential unstable wedges around the excavation as shown (refer with: Fig. 8) before any support was added to the excavation and after and after adding support to the excavation (refer with: Fig. 9). Once the factor of safety rose to 1.5 which was the design factor of safety, the support design was taken to be adequate. The support design shown (refer with: Fig. 10) was for 541 metre level. This was done for several other sites at the mine and various support designs were obtained, each design for each site.

Input data - Stereographic plot from Dips software

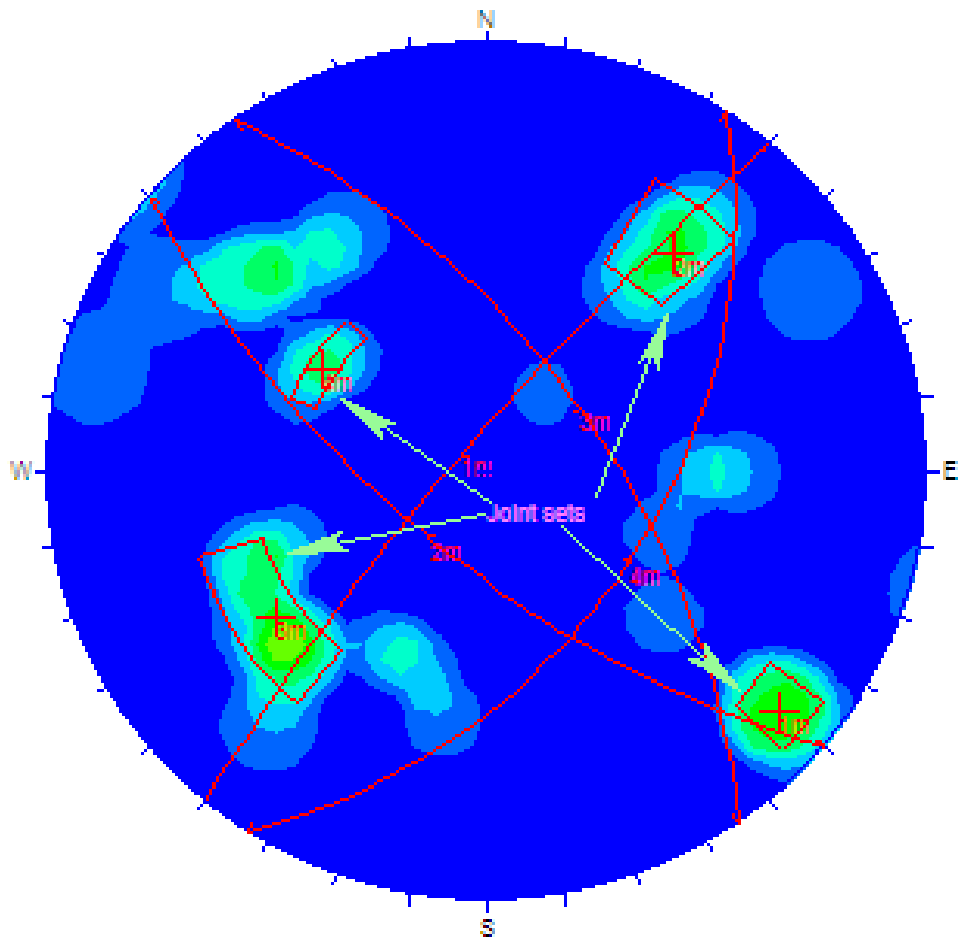

Fig. 7 Stereographic plot

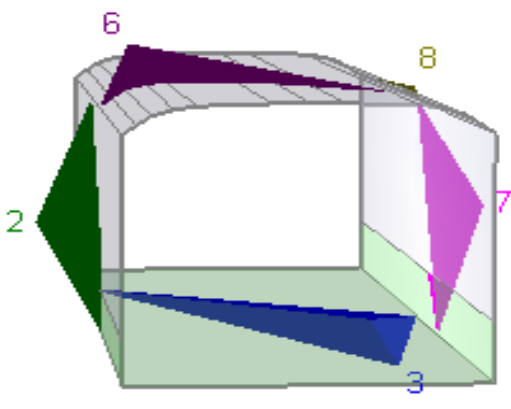

Fig. 8 Unsupported excavation

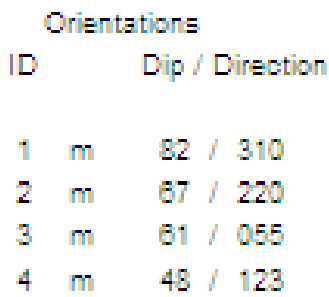

Equal Angle

Lower Hemisphere

34 Poles

34 Entries

Analysis results before support using UNWEDGE

Analysis results after support at a factor of safety of 1.5

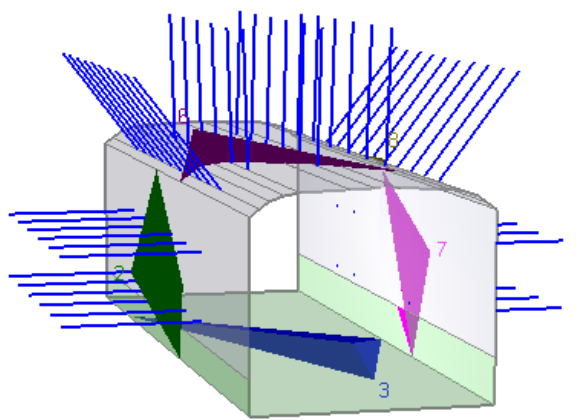

Fig. 9 Supported excavation

The plan and section view of support design at a factor of safety of 1.5 


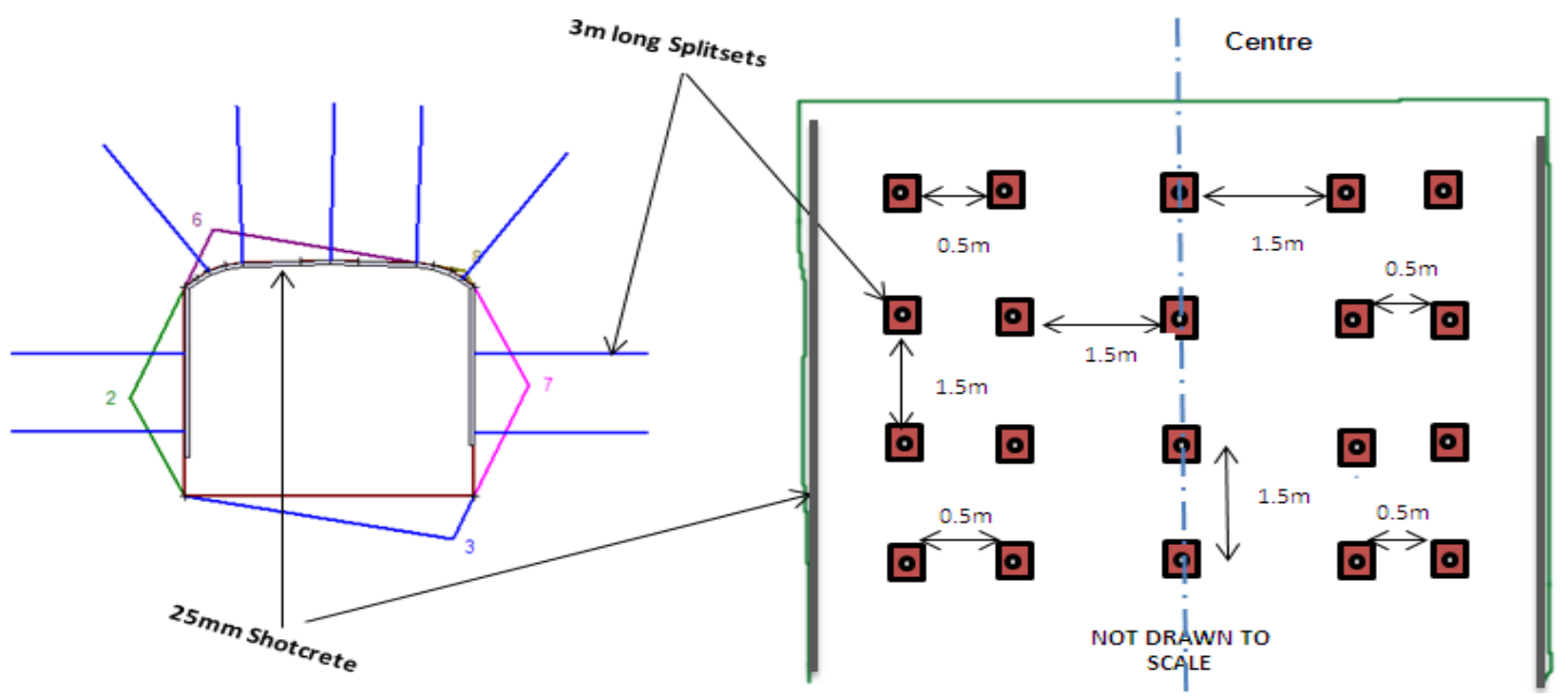

Fig. 10 Plan and section view of support design

For potential unstable wedges in the rockmass, the shape, size, orientation and apex height depend on the orientation and persistence of the planes of weakness (discontinuity). However, there is always a limit on the maximum apex height of the potential unstable wedges depending on the mine structure. For instance, at Chibuluma south mine, the average thickness of the crown pillar is $10 \mathrm{~m}$, which implies that the maximum apex height of a roof wedge is $10 \mathrm{~m}$. Therefore, in a case where UNWEDGE determined the apex height to be more than $10 \mathrm{~m}$, there was need to correct the height, the volume, the support pressure and hence the factor of safety. The formula below (refer with: Eq. 2) was derived to calculate this adjusted factor of safety.

$$
\text { Adjusted } \mathrm{FS}=\mathrm{FS}_{\mathrm{i}} \times\left[\frac{\mathrm{h}_{\mathrm{i}}{ }^{3}}{\mathrm{~h}_{\mathrm{i}}{ }^{3}-\left(\mathrm{h}_{\mathrm{i}}-10\right)^{3}}\right]
$$

Where $\mathrm{FS}_{\mathrm{i}}=$ Initial factor of safety provided by UNWEDGE and

$\mathrm{h}_{\mathrm{i}}=$ Initial height of wedge provided by UNWEDGE

(The above equation was derived by the author, Pardon Sinkala)

\section{Conclusion}

A detailed study using available Geological and Geotechnical information from drill cores and underground mapping was made to determine the likely behaviour of the rockmass and stability of the excavations. Bieniawski's Geomechanics classification system showed that the ground condition ranges from fair to good at Chibuluma South mine. Care was taken on the major factors affecting the accuracy of model prediction of ground conditions. These factors were the excavation geometry and material properties as input data. Therefore, there is need for periodical reviews on laboratory testing of rock samples so as to obtain updated data on strength properties of the rockmass and the excavation geometry as input data should be as close as possible to the actual mine excavation. In order to achieve a more proactive hazard alleviation in terms of safety and economics, there is need for an intensified geotechnical data collection and support design, which implies that a mine must have an adequate workforce which is competent, and must also have proper ground control instruments in place. Fractures in the rockmass at Chibuluma mine were caused by induced stresses and blast damage. Blast damage is unavoidable with conventional drill and blast mining methods [3]. However, minimal blast damage can be achieved by using controlled drilling and blasting. Using Numerical and Analytical design methods, ground support was reviewed and improved for the access crosscuts, orebody/footwall drives and room crosscuts. The proposed support designs were adequate and cost effective. 


\section{References}

[1] Bandis, S. C.Barton, N.R and Christianson, M. (1985) Application of a new numerical model of joint behaviour to rock mechanics problems, Fundamentals of Rock Joints.

[2] B.H.G. Brady and E.T. Brown (2005), Rock Mechanics for underground mining, $3^{\text {rd }}$ Edition, USA, pp. 312-338.

[3] E. Hoek and E.T. Brown (1982), Underground Excavation in Rock, Institute of Mining and Metallurgy, London.

[4] E. Hoek, P.K. Kaiser, W.F. Bawden (1989), Support for Underground excavation in Rock, Brookfield, U.S.A.

[5] J.N. de la Vergne (2003), Hard Rock Miner's Handbook, Ontario, pp. 13-34.

[6] Krishna, R. \& Chanda, M. Rock Mechanics Lecture notes. University of Zambia. Mining Engineering Department.

[7] M.L. Geremic, A.A Balkema (1987), Ground Mechanics in Hard Rock Mining. Rotterdam, Netherland.

[8] Richard E. Goodman; "Introduction to Rock Mechanics", $2^{\text {nd }}$ Edition, New York, 1989, pp. 221 291.

[9] William G. Pariseau., (2007), Design Analysis in Rock Mechanics, Taylor and Francis/ Balkema, Netherland, pp. 175-226. 